\title{
PWAR6 interacts with miR-106a-5p to regulate the osteogenic differentiation of human periodontal ligament stem cells
}

\author{
JUAN XIANG and YING BIAN \\ Department of Oral and Maxillofacial Surgery, Jingmen No. 1 People's Hospital, Jingmen, Hubei 448000, P.R. China
}

Received November 22, 2019; Accepted May 6, 2020

DOI: $10.3892 / \mathrm{mmr} .2021 .11907$

\begin{abstract}
Human periodontal ligament stem cells (hPDLSCs) associated with bone regeneration serve an important role in the treatment of periodontal disease. Long non-coding RNAs are involved in the osteogenesis of multiple stem cells and can act as a sponge of microRNAs (miRs). The present study aimed to investigate the interaction between Prader Willi/Angelman region RNA 6 (PWAR6) and miR-106a-5p, as well as their influences on the osteogenic differentiation of hPDLSCs. hPDLSCs were isolated and cultured in osteogenic medium $(\mathrm{OM})$ or growth medium (GM) for 7 days prior to transfection with PWAR6 overexpression vector, short hairpin RNA PWAR6 or miR-106a-5p mimic. The expression levels of runt-related transcription factor 2, osteocalcin and bone morphogenetic protein 2 (BMP2) were detected by western blotting and reverse transcription-quantitative PCR (RT-qPCR), and the expression levels of PWAR6, miR-106a-5p and alkaline phosphatase (ALP) were determined by RT-qPCR. ALP activity assays and Alizarin red staining were performed to detect osteogenesis and mineralization, respectively. Luciferase activities of wild-type and mutant PWAR6 and BMP2 were assessed by conducting a dual-luciferase reporter assay. The results indicated that PWAR6 expression was upregulated in OM-incubated hPDLSCs compared with GM-incubated hPDLSCs, and PWAR6 overexpression increased the osteogenic differentiation and mineralization of hPDLSCs compared with the corresponding control group. By contrast, miR-106a-5p expression was downregulated in OM-incubated hPDLSCs compared with GM-incubated hPDLSCs. PWAR6 acted as a sponge of miR-106a-5p and PWAR6 overexpression promoted the osteogenesis of miR-106a-5p mimic-transfected hPDLSCs. BMP2 was predicted as a target gene of miR-106a-5p. Collectively, the results indicated that PWAR6
\end{abstract}

Correspondence to: Dr Ying Bian, Department of Oral and Maxillofacial Surgery, Jingmen No. 1 People's Hospital, 168 Xiangshan Avenue, Duodao, Jingmen, Hubei 448000, P.R. China E-mail: biany_ying@163.com

Key words: bone morphogenetic protein 2, human periodontal ligament cells, microRNA-106a-5p, osteogenic differentiation, PWAR6 displayed a positive influence on the osteogenic differentiation of hPDLSCs. The results of the present study demonstrated that the PWAR6/miR-106a-5p interaction network may serve as a potential regulatory mechanism underlying hPDLSCs osteogenesis.

\section{Introduction}

Periodontal disease is a chronic, inflammatory disease characterized by the loss of supporting bone and periodontal tissue around the teeth, and is highly prevalent and can affect up to $90 \%$ of the worldwide population $(1,2)$. Chronic inflammation reduces the regeneration of periodontal tissues and inhibits the osteogenic differentiation of periodontal ligament stem cells (PDLSCs) (3). Human PDLSCs (hPDLSCs) are the most common cells in periodontal membranes, which constantly form new fibers and bones, resulting in remodeling of the alveolar bone (4). hPDLSCs serve a critical function in repairing periodontal tissues and are among the vital seed cells required for periodontal regeneration (5). However, inflammation can reduce the bone regeneration ability of hPDLSCs, leading to irreversible damage (6-8). Multiple factors have been reported to be involved in the osteogenic differentiation of hPDLSCs, including bone morphogenetic protein 2 (BMP2), alkaline phosphatase (ALP), microRNAs (miRNAs/miRs) and runt-related transcription factor 2 (Runx2) (9-17). In addition to miRNAs, long non-coding RNAs (lncRNAs) also display regulatory effects on hPDLSCs $(1,8,11,18)$.

Non-coding RNAs (ncRNAs), which comprise $298 \%$ of transcriptomes, display a variety of biological functions, including modulating gene expression and DNA synthesis $(19,20)$. Conventionally, ncRNAs refer to ribosomal RNAs and transfer RNAs, which serve a vital role in protein synthesis (21). A number of other types of ncRNAs, including small nuclear RNAs, miRNAs and IncRNAs, have also been discovered and investigated (20). IncRNAs serve different roles in gene expression via complex molecular mechanisms (20). For example, IncRNA-POIR, maternally expressed 3, XR_111050 and H19 imprinted maternally expressed transcript regulate the osteogenic differentiation of multiple types of stem cells $(18,22-24)$. In addition to their functions in cells, lncRNAs also act as sponges of miRNAs, displaying the hierarchical regulatory potency of one ncRNA over another $(25,26)$. For example, IncRNA-malate dehydrogenase acts as a sponge for miR-133 and miR-135 by preventing 
the miRNAs from targeting mastermind like transcriptional coactivator 1 and myocyte enhancer factor 2C (27). By binding to the 3'-untranslated regions of mRNAs, miRNAs regulate their expression, whereas lncRNAs serve as sponges of miRNAs by by preventing the aforementioned process (8).

The role of Prader Willi/Angelman region RNA 6 (PWAR6) in cancer and other diseases has not yet been fully elucidated. IncRNA PWAR6 has been recognized as a potential imprinted gene (28). A previous study verified its importance in the pathogenesis of Prader-Willi syndrome (29), but it is also associated with patient survival during glioma progression (30).

The present study investigated the expression of PWAR6 in hPDLSCs and its influence on the osteogenic differentiation of hPDLSCs. The results indicated that PWAR6 could promote hPDLSC osteogenesis and suggested that the interaction between miR-106a-5p and PWAR6 affected the osteogenic differentiation of hPDLSCs.

\section{Materials and methods}

Cell culture and characterization. hPDLSCs were isolated from premolars extracted from patients (Age: 11-18 years old, four male and five female) who had not received pharmacological treatment for orthodontic treatment at Jingmen No. 1 People's Hospital (Jingmen, China) between September 2018 to May 2019. The present study was approved by the Ethics Committee of Jingmen No. 1 People's Hospital (approval no. Y20180831) and written consent was obtained from each participant.

Premolars were washed with PBS (cat. no. 10010023; Thermo Fisher Scientific, Inc.) supplemented with $1 \%$ penicillin-streptomycin $(100 \mathrm{U} / \mathrm{ml}$ penicillin; $100 \mu \mathrm{g} / \mathrm{ml}$ streptomycin; cat. no. 15140122; Thermo Fisher Scientific, Inc.). Periodontal ligament tissues were scraped, cut into small pieces and digested using collagenase I $(3 \mathrm{mg} / \mathrm{ml}$; Sigma-Aldrich; Merck KGaA) and dispase II (4 mg/ml; Sigma-Aldrich; Merck KGaA) for $1 \mathrm{~h}$ at $37^{\circ} \mathrm{C}$. To further isolate and purify the stem cells, single-cell suspensions of primary cells were cloned using the limiting-dilution method, as previously described $(31,32)$. Following digestion, the single-cell suspension was filtered through a $70 \mu \mathrm{m}$ strainer. Subsequently, half of the single-cell suspension was seeded $\left(60\right.$ cells $\left./ \mathrm{cm}^{2}\right)$ into $10-\mathrm{cm}$ tissue culture dishes in DMEM supplemented with 10\% FBS (cat. no. 10100147; Thermo Fisher Scientific, Inc.), $50 \mathrm{mg} / \mathrm{ml}$ streptomycin and $50 \mathrm{U} / \mathrm{ml}$ penicillin at $37^{\circ} \mathrm{C}$ with $5 \% \mathrm{CO}_{2}$. The non-adherent cells were removed 3 days later, and the culture medium was changed three times per week. When cells reached $80 \%$ confluency, the supernatant was removed, the cells were washed twice using PBS twice and $0.5 \%$ 10X Trypsin-EDTA (cat. no. 15400054; Thermo Fisher Scientific, Inc.) was added to the cells for $2 \mathrm{~min}$ at room temperature. $2 \mathrm{ml}$ DMEM/F12 with $10 \%$ FBS was added to terminate dissociation. After centrifugation at $1,500 \mathrm{x} \mathrm{g}$ for $3 \mathrm{~min}$ at room temperature, 2-3 ml DMEM/F12 supplemented with $1 \%$ penicillin-streptomycin and $10 \%$ FBS was added to the cells for subculture. P3 cells were used for subsequent experiments. Cell morphology was observed using an inverted phase contrast light microscope (DSZ2000X; Chongqing UOP Photoelectric Technology, Co., Ltd.).
For osteogenic induction, hPDLSCs were cultured in osteogenic medium (OM) consisting of $10 \mathrm{mmol} / \mathrm{l}$ $\beta$-glycerophosphate sodium (cat. no. 50020; Sigma-Aldrich; Merck KGaA), $50 \mu \mathrm{g} / \mathrm{ml}$ L-ascorbic acid (cat. no. 795437; Sigma-Aldrich; Merck KGaA) and $100 \mathrm{mmol} / \mathrm{l}$ dexamethasone (Sigma-Aldrich; Merck KGaA) at $37^{\circ} \mathrm{C}$ with $5 \% \mathrm{CO}_{2}$. For the control group, hPDLSCs were cultured in growth medium (GM; cat. no. 112-500, Sigma-Aldrich; Merck KGaA). The medium was changed every two days and osteogenic induction duration was 21 days.

The cells were fixed with $4 \%$ paraformaldehyde (10 min) at $4^{\circ} \mathrm{C}$ and blocked in $1 \mathrm{X}$ PBS containing $10 \%$ normal goat serum (Thermo Fisher Scientific, Inc.) and $0.3 \mathrm{M}$ glycine for $1 \mathrm{~h}$ at room temperature. To analyze mesenchymal stem cell marker expression, passage 3 cells were incubated at room temperature for $45 \mathrm{~min}$ with the following FITC or PE-conjugated monoclonal antibodies: Anti-Cluster of differentiation (CD)73 (Clone AD2, cat. no. 561254, 1:60), anti-CD90 (Clone 5E10, cat. no. 555595, 1:50), anti-CD105 (Clone 266, cat. no. 561443, 1:1,000), anti-CD34 (Clone 581, cat. no. 560710, 1:50) and anti-CD45 (Clone HI30, cat. no. 562312, 1:50, all BD Biosciences). Subsequently, the cells were examined using a FACS Canto II flow cytometer (BD Biosciences) and analyzed using BD CellQuest Pro Software V1.2 (BD Biosciences).

Immunohistochemical staining. hPDLSCs were cultured in a 24-well plate. At $60 \%$ confluence, $0.5 \mathrm{ml} 4 \%$ paraformaldehyde (cat. no. MFCD00133991; Thermo Fisher Scientific, Inc.) was added into each well for $20 \mathrm{~min}$ at room temperature. After washing the cells with PBS (cat. no. 10010031; Thermo Fisher Scientific, Inc.) three times, 0.2\% Triton X-100 (cat. no. HFH10; Thermo Fisher Scientific, Inc.) was added to the cells for $30 \mathrm{~min}$, and subsequently, the cells were incubated with $3 \% \mathrm{H}_{2} \mathrm{O}_{2}$ for $10 \mathrm{~min}$ at room temperature. Cells were blocked in $10 \%$ normal serum (Thermo Fisher Scientific, Inc.) with $1 \%$ BSA (Thermo Fisher Scientific, Inc.) in TBS for $2 \mathrm{~h}$ at room temperature. Each well was incubated with $50 \mu$ l anti-vimentin (cat. no. ab193555; 1:200; Abcam) antibody for $2 \mathrm{~h}$ at $37^{\circ} \mathrm{C}$. After washing with PBS three times for 2 min each time, $50 \mu 1$ goat anti-rabbit IgG H\&L preadsorption secondary antibody (cat. no. ab96899; Abcam, 1:20,000) was added to each well for $20 \mathrm{~min}$ at $37^{\circ} \mathrm{C}$. The cells were then washed with PBS three times. Subsequently, a DAB Reagent kit (cat. no. PW017; Shanghai Sangong Pharmaceutical Co., Ltd.) was used and the cells were observed under a fluorescence microscope at x400 magnification).

Cell transfection. hPDLSCs $\left(4 \times 10^{5}\right)$ were transfected with $50 \mathrm{nmol}$ of PWAR6 overexpression vector (PWAR6-OE), empty negative vector control (NC) (pCMV6-XL4-PWAR6, cat. no. SC127195 and its empty control vector were purchased from OriGene Technologies, Inc.), short hairpin (sh)RNA negative control (cat. no. C03002, shNC, Suzhou GenePharma Co., Ltd.), shPWAR6 (TGCTATCCTATTCATTTAGTATA, Suzhou GenePharma Co., Ltd.), miR-106a-5p mimic (GAU GGACGUGACAUUCGUGAAAA, cat.no. miR10000103-1-5, Guangzhou RiboBio Co., Ltd.) or mimic control (MC, 5'-UUC UCCGAA CGUGUCACGUTT-3', Guangzhou RiboBio Co., Ltd.) using Lipofectamine ${ }^{\circledR} 2000$ transfection reagent (cat. no. 11668019; Thermo Fisher Scientific, Inc.) 
according to the manufacturer's protocols. Briefly, 0.8-1.0 $\mu \mathrm{g}$ of overexpression vectors, shRNAs miRNA mimics or their respective controls were diluted in $50 \mu 1$ DMEM medium (cat. no. 12491015; Thermo Fisher Scientific, Inc.). Similarly, 1-3 $\mu 1$ Lipofectamine $^{\circledR} 2000$ reagent was diluted in $50 \mu$ l DMEM medium and maintained at room temperature for $5 \mathrm{~min}$. Subsequently, the diluted DNA and Lipofectamine $2000^{\circledR}$ reagent were mixed together and incubated at room temperature for $20 \mathrm{~min}$. The mixed solution was added to the cells for $2 \mathrm{~h}$. Following a further incubation in DMEM at $37^{\circ} \mathrm{C}$ with $5 \% \mathrm{CO}_{2}$ for 24 or $48 \mathrm{~h}$, transfection efficiency was assessed.

ALP activity assay. ALP activity was detected using the Alkaline Phosphatase Assay kit (cat. no. ab83369; Abcam). hPDLSCs $\left(1 \times 10^{5}\right)$ were incubated with OM in 24-well plates for 7 days at room temperature. According to the manufacturer's protocol, $10 \mu \mathrm{l}$ ALP enzyme solution and $50 \mu 15 \mathrm{mM}$ para-nitrophenyl phosphate solution were added into each well and incubated at $25^{\circ} \mathrm{C}$ for $60 \mathrm{~min}$ in the dark. The reaction was terminated by adding $20 \mu \mathrm{l}$ stop solution. The absorbance of each well was measured at a wavelength of $405 \mathrm{~nm}$ using a microplate reader (cat. no. 11-120-533; Thermo Fisher Scientific, Inc.).

Alizarin red staining. Alizarin red staining was performed using the Alizarin Red S Staining kit (cat. no. 0223; ScienCell Research Laboratories, Inc.). According to the manufacturer's protocol, following aspiration of the culture medium, $1 \times 10^{5}$ cells were washed twice with $1 \mathrm{ml}$ PBS and fixed in $4 \%$ paraformaldehyde for $15 \mathrm{~min}$ at room temperature. Before cell staining, the fixative was removed, and cells were washed three times with $\mathrm{diH}_{2} \mathrm{O}$. After removing $\mathrm{diH}_{2} \mathrm{O}, 1 \mathrm{ml} 2 \%$ Alizarin Red S Stain solution was added to each well and incubated for 20-30 min at room temperature. Subsequently, the solution was removed, and cells were washed three to five times using

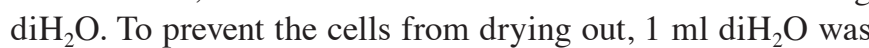
added to each well. The samples were observed under a light microscope at x400 magnification. Quantification of mineralization indicated by Alizarin red staining was performed using Image-Pro Plus (version 6.0; Media Cybernetics, Inc.).

Bioinformatics and dual-luciferase reporter assay. StarBase V2.0 (starbase.sysu.edu.cn) (33) was used to predict the target gene of PWAR6 and the dual-luciferase reporter assay was performed to investigate the findings. To assess whether miR-106a-5p targets PWAR6 and BMP2, this was examined using the luciferase pGL3-Basic vector (Promega Corporation). miR-106a-5p binding sites in wild-type (WT) and mutant (Mut) $P W A R 6$ and $B M P 2$ were analyzed by performing a dual-luciferase reporter assay using the Dual-Luciferase Reporter assay system (cat. no. E1910; Promega Corporation). Briefly, after aspirating the culture medium, $2 \times 10^{5}$ cells were washed two to three times using $1 \mathrm{X}$ PBS. Subsequently, 100-150 $\mu 11 \mathrm{X}$ passive lysis buffer (PLB) was added to the cells to ensure complete and even coverage of the cell monolayer. The plates were incubated for $15 \mathrm{~min}$ at room temperature with gentle agitation. After $24 \mathrm{~h}$, the cells were added to the luminometer tubes. Then, to each luminometer tube, $100 \mu$ l Luciferase Assay Reagent II was added and $20 \mu 1$ PLB was carefully transferred. The tube was placed in the luminometer (cat. no. E5311; Promega Corporation) and the reading was initiated. Finally, $100 \mu 1$ Stop \& Glo ${ }^{\circledR}$ Reagent was added to measure the activities. miR-106a-5p mimic was co-transfected with WT or MUT luciferase vector into 293T cells (American Type Culture Collection) using Lipofectamine ${ }^{\circledR} 2000$ (Invitrogen; Thermo Fisher Scientific, Inc.). Renilla luciferase activity was detected in the same method described above. After $48 \mathrm{~h}$ of transfection, activity was measured.

Western blotting. Following cell culture in OM for 7 days, hPDLSCs were assessed by western blotting. Total protein $\left(20 \mu \mathrm{g} /\right.$ lane) was extracted from hPDLSCs $\left(4 \times 10^{5}\right)$ using Mammalian Protein Extraction Reagent (cat. no. 78501; Thermo Fisher Scientific, Inc.). The protein concentration was determined using a BCA Protein Assay kit (cat. no. 23225; Thermo Fisher Scientific, Inc.) according to the manufacturer's protocols. Subsequently, $20 \mu \mathrm{g}$ protein lysate was separated via 12\% SDS-PAGE (cat. no. P0012A; Beyotime Institute of Biotechnology) and transferred to PVDF membranes (cat. no. FFP28; Beyotime Institute of Biotechnology). The membranes were blocked using $5 \%$ bovine serum albumin (cat. no. A1933; Sigma-Aldrich; Merck KGaA) for $2 \mathrm{~h}$ at room temperature. Subsequently, the membranes were incubated at $4^{\circ} \mathrm{C}$ overnight with the following primary antibodies: Anti-Osteocalcin (OCN; cat. no. ab93876; 1:500; Abcam), anti-Runx2 (cat. no. ab23981; 1:1,000; Abcam), anti-BMP2 (cat. no. ab214821; 1:1,000; Abcam) and anti-GADPH (cat. no. ab8245 or ab205719; 1:1,000; Abcam). Following primary incubation, the membranes were incubated with a horseradish peroxidase-conjugated goat anti-rabbit (cat. no. ab6721; 1:2,000; Abcam) or goat anti-mouse IgG H\&L (cat. no. ab150113, 1:200, Abcam) secondary antibody at room temperature for $1 \mathrm{~h}$. Protein bands were visualized using enhanced chemiluminescence reagent (cat. no. FD8000; Fdbio Science). Protein expression levels were quantified using Image J software (Version 1.8.0; National Institutes of Health) with GAPDH as the loading control.

Reverse transcription-quantitative PCR (RT-qPCR). Total RNA was extracted from the nuclei and cytoplasm of hPDLSCs using the Cytoplasmic and Nuclear RNA Purification kit (cat. no. 21000; Norgen Biotek Corp.). Total RNA was extracted from hPDLSCs using TRIzol ${ }^{\circledR}$ reagent (cat. no. 15596018; Thermo Fisher Scientific, Inc.). RNA concentration and optical density (1.8-2.1) were detected using a Nanodrop 8000 spectrophotometer (cat. no. ND-8000-GL; Thermo Fisher Scientific, Inc.) and RNA integrity was assessed via $1 \%$ agarose gel electrophoresis (cat. no. G442001; Thermo Fisher Scientific, Inc.). Total RNA was reverse transcribed into cDNA using the PrimeScript RT Reagent kit with gDNA Eraser (cat. no. RR047B; Takara Biotechnology Co., Ltd.). Briefly, $2 \mu 1$ 5X gDNA Eraser Buffer, $1 \mu \mathrm{lgDNA}$ Eraser, $1 \mu \mathrm{g}$ total RNA and $10 \mu \mathrm{l}$ RNase-free $\mathrm{dH}_{2} 0$ were mixed together and incubated using an Applied Biosystems Veriti PCR system (cat. no. 4484073; Thermo Fisher Scientific, Inc.) for 2 min at $42^{\circ} \mathrm{C}$. Subsequently, $1 \mu \mathrm{l}$ PrimeScript RT Enzyme Mix I, $4 \mu \mathrm{l}$ RT primer Mix, $4 \mu \mathrm{l}$ 5X PrimeScript Buffer 2 and $1 \mu 1$ RNase Free $\mathrm{dH}_{2} 0$ were added to $10 \mu \mathrm{l}$ sample and incubated at $37^{\circ} \mathrm{C}$ for $15 \mathrm{~min}$, followed by incubation at $85^{\circ} \mathrm{C}$ for $5 \mathrm{sec}$. qPCR was performed using the 7500 Real-Time PCR system 
(cat. no. 4351105; Thermo Fisher Scientific, Inc.) using SYBR green (Invitrogen; Thermo Fisher Scientific, Inc.) with the following thermocycling conditions: $95^{\circ} \mathrm{C}$ for $1 \mathrm{~min}, 95^{\circ} \mathrm{C}$ for $5 \mathrm{sec}$ and $60^{\circ} \mathrm{C}$ for $30 \mathrm{sec}$, for a total of 40 cycles, $72^{\circ} \mathrm{C}$ for $30 \mathrm{sec}$, with a final extension at $72^{\circ} \mathrm{C}$ for $90 \mathrm{sec}$. Primers used were purchased from Guangzhou RiboBio Co., Ltd. and are listed in Table I. Expression levels were quantified using the $2^{-\Delta \Delta \mathrm{Cq}}$ method (34) and normalized to the internal reference genes U6 and GAPDH.

Statistical analysis. Statistical analyses were performed using SPSS software (version 16.0; SPSS, Inc.). Data are presented as the mean \pm SEM. All experiments were performed in triplicate. Comparisons among multiple groups were analyzed using one-way ANOVA followed by Tukey's post hoc test. The unpaired Student's t test was used for comparisons between two groups. $\mathrm{P}<0.05$ was considered to indicate a statistically significant difference.

\section{Results}

Cellular morphology and identification of hPDLSCs. hPDLSC cellular morphology was observed using P3 cells. Growing adherent cells were long and spindle-shaped and appeared in a radial or vortex-shaped close arrangement. Immunohistochemical staining results indicated that vimentin was expressed, which indicated that hPDLSCs were vimentin positive (Fig. 1A). hPDLSCs were CD73 (99.34\%), CD90 (99.88\%) and CD105 (99.67\%) positive, but CD34 (0.41\%) and CD45 (0.58\%) negative (Fig. 1B).

PWAR6 expression during the osteogenic induction and differentiation of hPDLSCs. hPDLSCs were cultured with $\mathrm{OM}$ to induce osteogenic differentiation. The expression levels of PWAR6 and osteogenic markers, including RUNX2, OCN, $B M P 2$ and $A L P$, in hPDLSCs were measured at 0, 3, 7, 14 and 21 days following osteogenic induction. The expression levels of PWAR6 and the osteogenic markers gradually increased in a time-dependent manner in the OM-incubated group. By contrast, following treatment with GM, the expression levels of PWAR6 and the osteogenic markers were not significantly altered among hPDLSCs incubated for different periods of time (Fig. 1C-G).

PWAR6 promotes the osteogenic differentiation of hPDLSCs. Based on the observation that the expression levels of PWAR6 and the osteogenic markers displayed a similar trend during hPDLSC osteogenic induction, the possible role of PWAR6 in hPDLSC osteogenic differentiation was investigated. A PWAR6 overexpression lentiviral plasmid (PWAR6-OE) and a PWAR6 knockdown lentiviral plasmid (shPWAR6) were constructed. Transfection efficiency was assessed by performing RT-qPCR, which indicated that PWAR6-OE significantly increased $P W A R 6$ expression, whereas shPWAR6 significantly reduced PWAR6 expression in hPDLSCs compared with the corresponding negative control groups (Fig. 2A). Based on the finding that significant differences in gene expression were observed at 7 days post-osteogenic induction, the expression levels of $R U N X 2, O C N$ and $B M P 2$ in the transfected hPDLSCs were detected after 7 days of culture
Table I. Primer sequences used for reverse transcription-quantitative PCR.

\begin{tabular}{ll}
\hline Gene & \multicolumn{1}{c}{ Sequence (5'-3') } \\
\hline PWAR6 & F: GCCTACATGATGGGCAGTTT \\
& R: ACAACCAAAAGCAAGCCAAC \\
RUNX2 & F: AGTAGCCAGGTTCAACGATCTGA \\
& R: GACTGTTATGGTCAAGGTGAAACTCTT \\
OCN & F: CGCTACCTGTATCAATGGCTGG \\
& R: ATGTGGTCAGCCAACTCGTCA \\
BMP2 & F: GCCTGCTTCGCCATCT \\
& R: TGCCTCCTCCTTCTCCC \\
GAPDH & F: TGGATTTGGACGCATTGGTC \\
& R: TTTGCACTGGTACGTGTTGAT \\
ALP & F: AACACCAATGTAGCCAAG \\
U6 & R: TCGGGCAGCGGTTACTGT \\
& F: GCTTCGGCAGCACATATACTAAAAT \\
microRNA- & F: GATGCTCAAAAAGTGCTTACAGTGCA \\
$106 a-5 p$ & R: TATGGTTGTTCTGCTCTCTGTCTC
\end{tabular}

PWAR6, Prader Willi/Angelman region RNA 6; RUNX2, runt-related transcription factor 2; OCN, osteocalcin; BMP2, bone morphogenetic protein 2; ALP, alkaline phosphatase.

in OM. The results indicated that PWAR6-OE significantly upregulated $R U N X 2, O C N$ and $B M P 2$ expression levels in hPDLSCs, whereas PWAR6 knockdown significantly downregulated the mRNA expression levels of osteogenic marker genes compared with the corresponding negative control groups (Fig. 2B). Similar but less significant regulatory effects of PWAR6 on Runx2, OCN and BMP2 expression levels were observed at the protein level (Fig. 2C). The effect of PWAR6 on hPDLSC osteogenic differentiation was investigated by performing Alizarin red staining and ALP activity assays. The PWAR6-OE group displayed significantly increased mineralization and ALP activity compared with the negative control group. By contrast, mineralization and ALP activity were significantly decreased in the PWAR6 knockdown group compared with the shNC group (Fig. 2D-F).

PWAR6 acts as a sponge of miR-106a-5p. To determine whether PWAR6 acted as a sponge of miR-106a-5p, StarBase was used to predict the binding sites between miR-106a-5p and PWAR6 (Fig. 3A). Subsequently, the expression of PWAR6 in the cytoplasm and nuclei of hPDLSCs was detected, and the results indicated that PWAR6 expression was significantly higher in the cytoplasm compared with the nucleus (Fig. 3B). A dual-luciferase reporter assay was performed, which suggested that miR-106a-5p mimic significantly inhibited the luciferase activity of the PWAR6-WT reporter, but displayed a limited effect on the PWAR6-Mut reporter compared with the negative control group (Fig. 3C). Furthermore, PWAR6 expression was negatively associated with miR-106a-5p expression in hPDLSCs, as indicated by PWAR6 overexpression reducing miR-106a-5p expression levels and PWAR6 
A
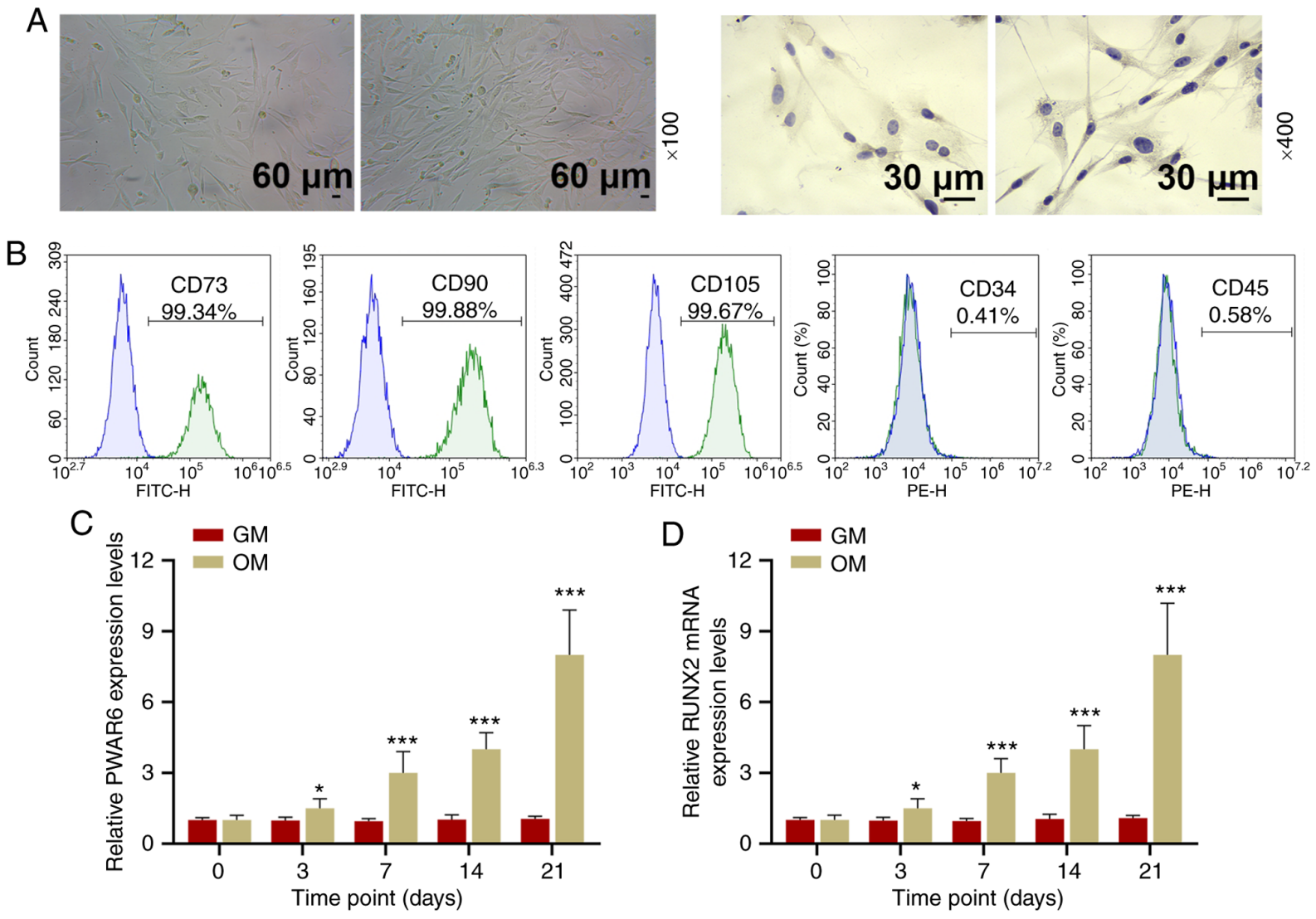

$\mathrm{D}$
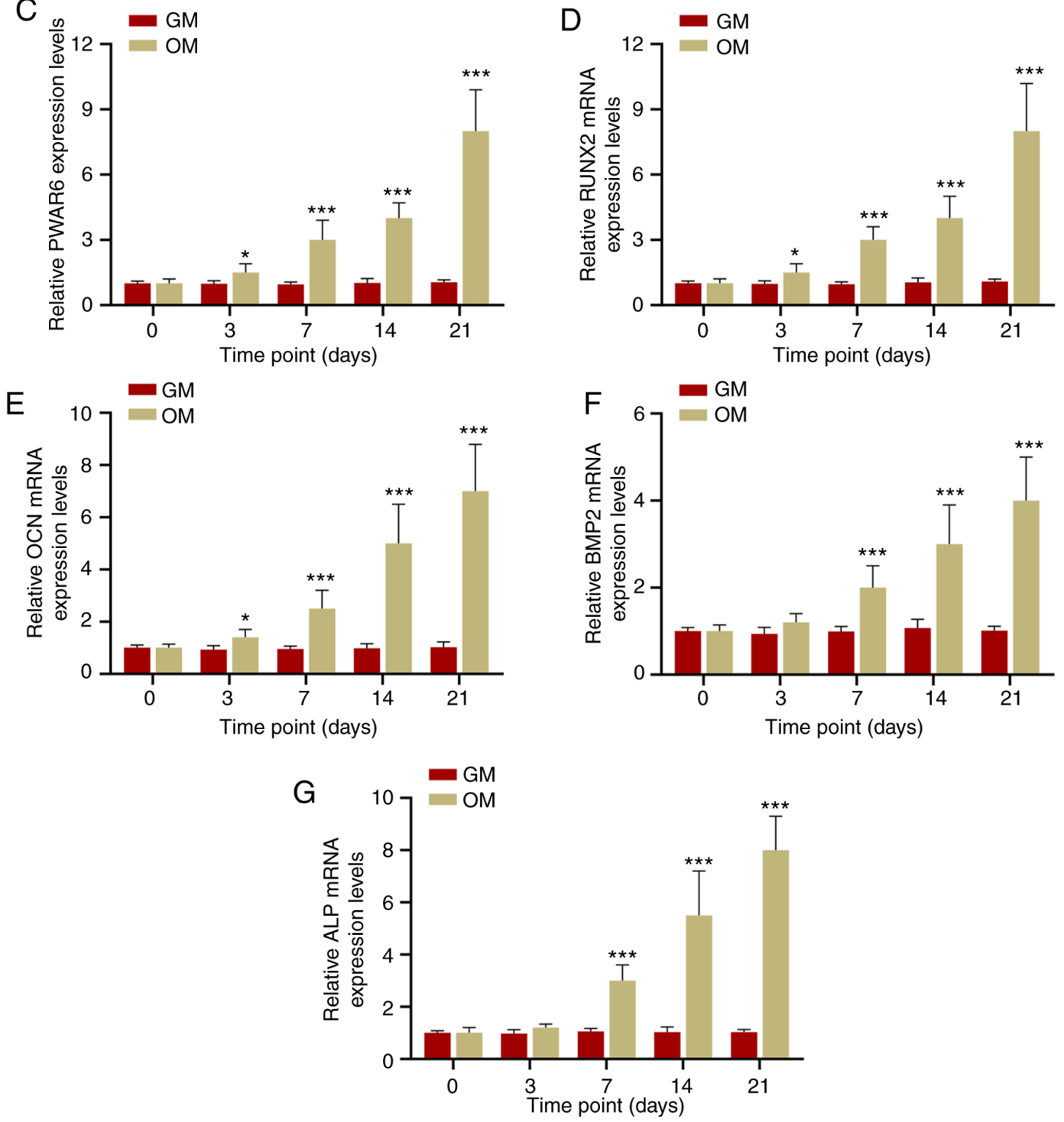

Figure 1. PWAR6 is upregulated during the osteogenic induction of hPDLSCs. (A) hPDLSC cell morphology was detected by microscopy (left:light microscopy, right: Immunohistochemical staining observed using fluorescence microscopy). (B) Flow cytometric analysis indicated that hPDLSCs were CD73+, CD90+, CD105+, CD34- and CD45-. Reverse transcription-quantitative PCR was performed to detect the expression levels of (C) PWAR6, (D) RUNX2, (E) $O C N$, (F) BMP2 and (G) ALP in hPDLSCs cultured in OM or GM for 0-21 days. ${ }^{*} \mathrm{P}<0.05$ and ${ }^{* * *} \mathrm{P}<0.001$ vs. GM. hPDLSCs, human periodontal ligament stem cells; CD, cluster of differentiation; GM, growth medium; OM, osteogenic medium.

knockdown increasing miR-105a-5p expression levels in hPDLSCs compared with the corresponding negative control groups (Fig. 3D). In addition, miR-106a-5p expression levels were significantly downregulated in hPDLSCs on days 7-21 of osteogenic induction compared with the GM-incubated group (Fig. 3E). 

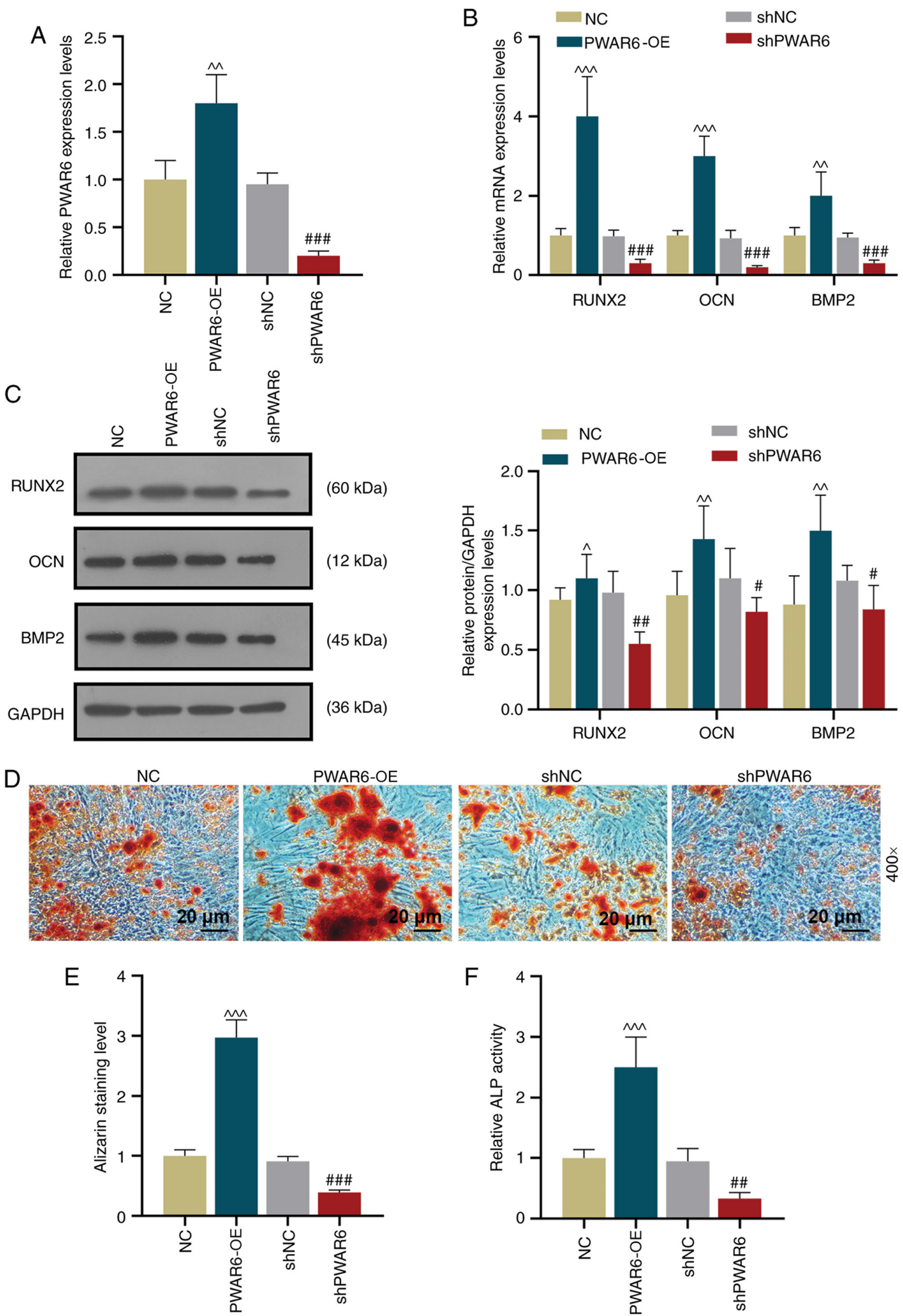

Figure 2. PWAR6 overexpression increases the osteogenic differentiation and mineralization of human periodontal ligament stem cells. (A) RT-qPCR was performed to detect PWAR6 expression level following transfection with $P W A R 6-\mathrm{OE}$, shPWAR6, NC or $\operatorname{shNC}\left({ }^{\wedge} \mathrm{P}<0.01 \mathrm{vs}\right.$. $\mathrm{NC}$; ${ }^{\# \#} \mathrm{P}<0.001 \mathrm{vs}$. shNC). (B) RT-qPCR was performed to detect RUNX2, OCN and BMP2 mRNA expression levels following transfection. (C) Following transfection, protein expression levels were determined by western blotting for Runx2, OCN and BMP2 $\left({ }^{\wedge} \mathrm{P}<0.05,{ }^{\wedge} \mathrm{P}<0.01\right.$ and ${ }^{\wedge \wedge}{ }^{\wedge} \mathrm{P}<0.001$ vs. NC; ${ }^{\# P} \mathrm{P}<0.05$, ${ }^{\# \#} \mathrm{P}<0.01$ and ${ }^{\# \# \#} \mathrm{P}<0.001$ vs. shNC). Osteogenesis was (D) determined by Alizarin red staining and (E) quantified. (F) Mineralization was assessed by performing an ALP activity assay. $\left({ }^{\wedge \wedge} \mathrm{P}<0.001\right.$ vs. NC; ${ }^{\# \#} \mathrm{P}<0.01$ and ${ }^{\# \# \#} \mathrm{P}<0.01$ vs. shNC). PWAR6-OE, PWAR6 overexpression vector; NC, negative control; sh, short hairpin RNA; RT-qPCR, reverse transcription-quantitative PCR; Runx2, runt-related transcription factor 2; OCN, osteocalcin; BMP2, bone morphogenetic protein 2; ALP, alkaline phosphatase. 
A

hsa-miR-106a-5p Target: $5^{\prime}$ guaagauggaaaUUAGCACUUUu $3^{\prime}$

| || || || |

miRNA: 3 ' gauggacgugacAUUCGUGAAAa 5
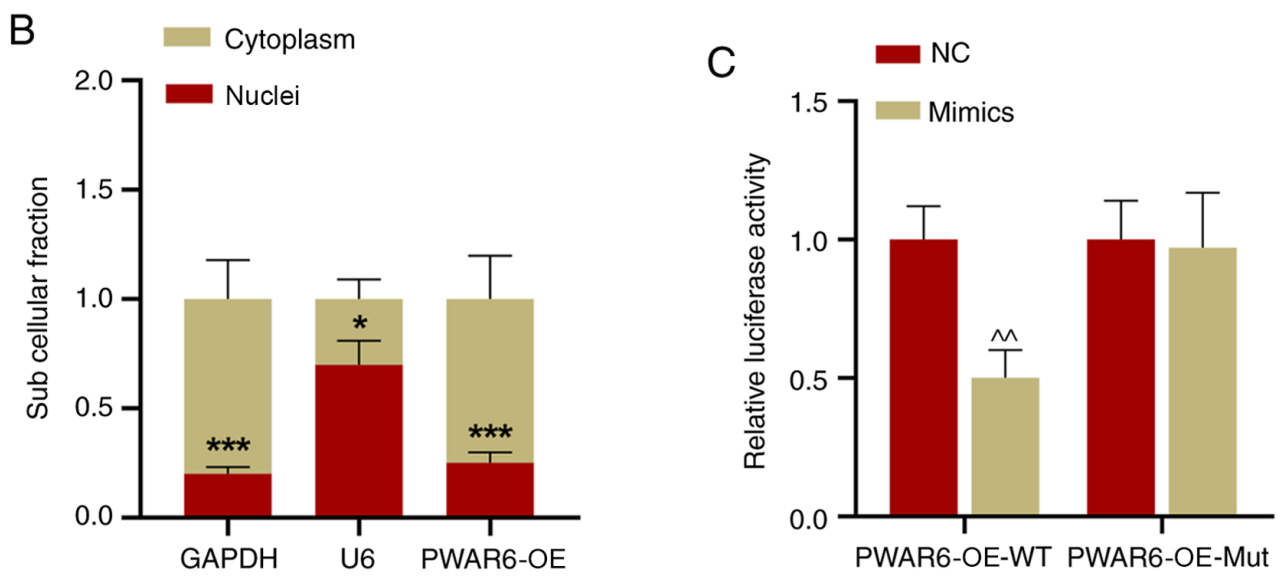

$\mathrm{D}$

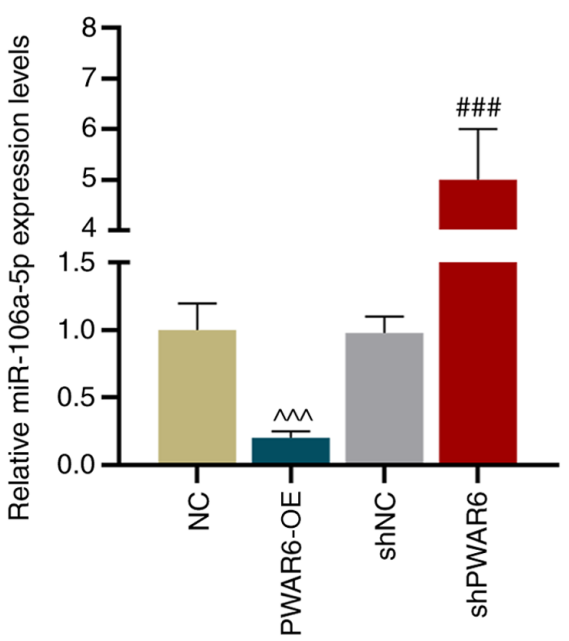

E

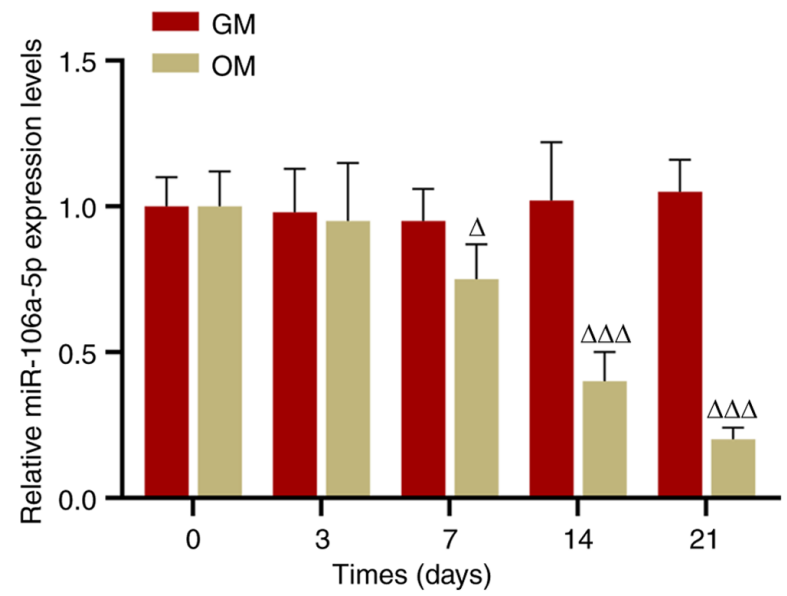

Figure 3. PWAR6 serves as a sponge of miR-106a-5p. (A) StarBase was used to predict the binding site between miR-106a-5p and PWAR6. (B) RT-qPCR was performed to detect PWAR6 expression levels in the cytoplasm and nuclei of hPDLSCs ( ${ }^{*} \mathrm{P}<0.05$ and ${ }^{* * *} \mathrm{P}<0.01$ vs. cytoplasm). (C) A dual-luciferase reporter assay was performed to detect luciferase activities of PWAR6-WT and PWAR6-Mut in miR-106a-5p mimic- and mimic control-transfected cells $\left({ }^{\wedge} \mathrm{P}<0.01\right.$ vs. NC). (D) RT-qPCR was performed to detect miR-106a-5p expression levels in PWAR6-OE-, shPWAR6-, NC- and shNC- transfected hPDLSCs $\left({ }^{\wedge \wedge} \mathrm{P}<0.001\right.$ vs. NC; ${ }^{\# \#} \mathrm{P}<0.001$ vs. shNC). (E) RT-qPCR was performed to detect miR-106a-5p expression levels in hPDLSCs cultured in GM or OM for $0-21$ days $\left({ }^{\Delta} \mathrm{P}<0.05\right.$ and ${ }^{\triangle \triangle \Delta} \mathrm{P}<0.001$ vs. GM). miR, microRNA; RT-qPCR, reverse transcription-quantitative PCR; hPDLSCs, human periodontal ligament stem cells; PWAR6-OE, PWAR6 overexpression vector; sh, short hairpin RNA; NC, negative control; GM, growth medium; OM, osteogenic medium; WT, wild-type; Mut, mutant.

PWAR6 negatively regulates miR-106a-5p during osteogenic differentiation. Based on the finding that PWAR6 sponged miR-106a-5p, the present study further analyzed how the relationship between PWAR6 and miR-106a-5p altered hPDLSCs osteogenesis. The results demonstrated that miR-106a-5p expression was significantly increased in miR-106a-5p mimic-transfected cells compared with control and mimic control-transfected cells (Fig. 4A). In addition, the results indicated that miR-106a-5p mimic significantly increased the expression level of miR-106a-5p compared with the corresponding control group, but PWAR6-OE attenuated the effect of miR-106a-5p mimic on miR-106a-5p expression levels (Fig. 4B). Similarly, at day 7 of osteogenic induction, miR-106a-5p mimic significantly downregulated PWAR6-OE-induced RUNX2,
$O C N$ and $B M P 2$ mRNA expression levels in hPDLSCs compared with the $\mathrm{MC}+P W A R 6-\mathrm{OE}$ group (Fig. 4C). Similar effects of miR-106a-5p mimic and PWAR6-OE on Runx2, $\mathrm{OCN}$ and BMP2 expression were also observed at the protein level; however, the effects of PWAR6-OE on OCN expression were significantly altered by miR-106a-5p mimic (Fig. 4D). In addition, hPDLSCs were analyzed by Alizarin red staining and ALP activity assays. The results indicated that miR-106a-5p mimic attenuated PWAR6-OE-induced mineralization and ALP activity in hPDLSCs (Fig. 4E-G).

BMP2 is the target gene of miR-106a-5p. The downstream target of miR-106a-5p was predicted using StarBase, and the binding site between $B M P 2$ and miR-106a-5p was predicted 

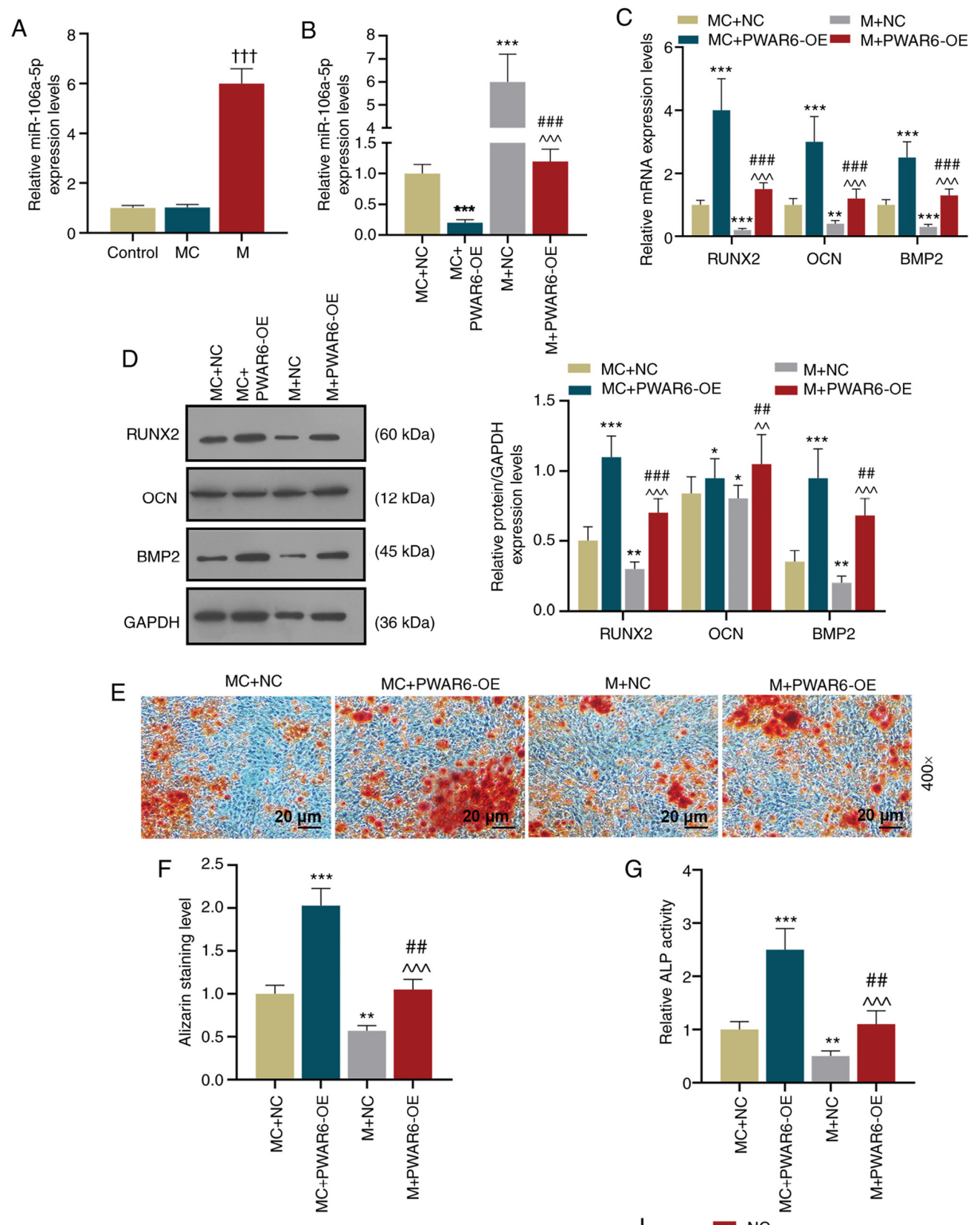

$\mathrm{M}+\mathrm{NC} \quad \mathrm{M}+\mathrm{PWAR6}-\mathrm{OE}$

$\mathrm{H}$
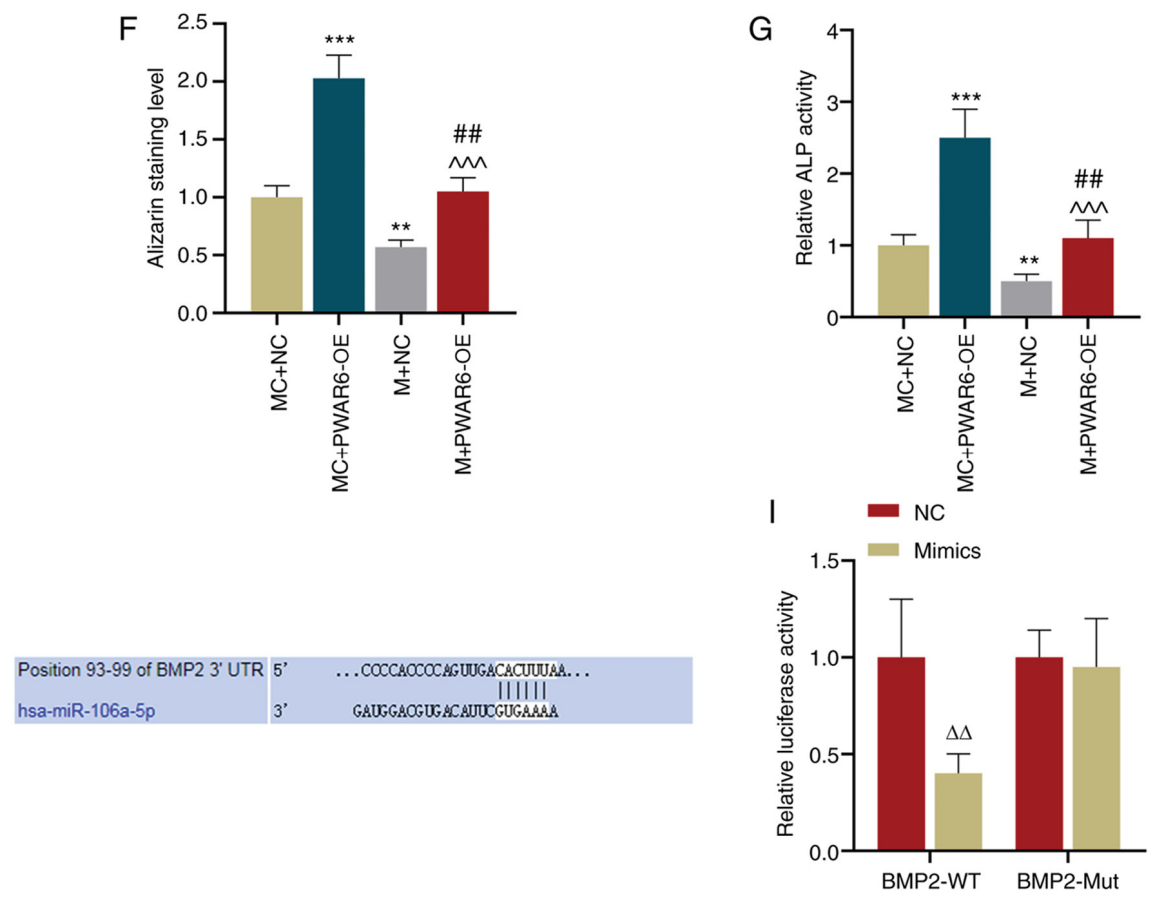

Figure 4. PWAR6 negatively regulates miR-106a-5p. BMP2 was identified as a target gene of miR-106a-5p. (A) RT-qPCR was performed to detect miR-106a-5p expression levels in transfected hPDLSCs ( ${ }^{\dagger} \mathrm{P}<0.001 \mathrm{vs}$. MC). (B) RT-qPCR was performed to detect miR-106a-5p expression levels in co-transfected hPDLSCs $\left({ }^{* * * *} \mathrm{P}<0.001\right.$ vs. MC + NC; ${ }^{\# \# \#} \mathrm{P}<0.001$, vs. MC $+P W A R 6-\mathrm{OE} ;{ }^{\wedge \wedge} \mathrm{P}<0.001$ vs. $\left.\mathrm{M}+\mathrm{NC}\right)$. (C) RT-qPCR was performed to detect RUNX2, OCN and

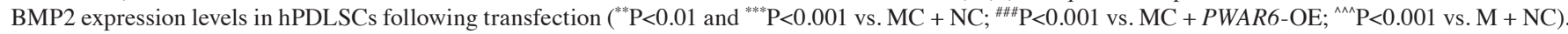
Protein expression levels were (D) determined by western blotting and (E) semi-quantified for Runx2, OCN and BMP2 in hPDLSCs following transfection $\left({ }^{*} \mathrm{P}<0.05,{ }^{* * *} \mathrm{P}<0.01\right.$ and ${ }^{* * *} \mathrm{P}<0.001$ vs. $\mathrm{MC}+\mathrm{NC}$; ${ }^{\# \#} \mathrm{P}<0.01$ and ${ }^{\# \# \#} \mathrm{P}<0.001$ vs. $\mathrm{MC}+P W A R 6-\mathrm{OE} ;{ }^{\wedge} \mathrm{P}<0.01$ and ${ }^{\wedge \wedge} \mathrm{P}<0.001$ vs. M $\left.+\mathrm{NC}\right)$. Osteogenesis was (E) determined by Alizarin red staining and (F) quantified. (G) Mineralization was determined by performing an ALP activity assay $\left({ }^{* *} \mathrm{P}<0.01\right.$ and ${ }^{* * * *} \mathrm{P}<0.001$ vs. $\mathrm{MC}+\mathrm{NC} ;{ }^{\# \#} \mathrm{P}<0.01$ vs. $\mathrm{MC}+\mathrm{PWAR6}-\mathrm{OE} ;{ }^{\wedge \wedge} \mathrm{P}<0.001$ vs. $\mathrm{M}+\mathrm{NC}$ ). (H) StarBase was used to predict the binding site between BMP2 and miR-106a-5p. (I) A dual-luciferase reporter assay was performed to detect the luciferase activities of BMP2-WT and BMP2-Mut in miR-106a-5p mimic- and mimic control-transfected cells ( ${ }^{\Delta} \mathrm{P}<0.01$ vs. NC). miR, microRNA; RT-qPCR, Reverse transcription-quantitative PCR; hPDLSCs, human periodontal ligament stem cells; MC, miR-106a-5p mimic control; NC, negative control; M, miR-106a-5p mimic; Runx2, runt-related transcription factor 2; OCN, osteocalcin; BMP2, bone morphogenetic protein 2; ALP, alkaline phosphatase; WT, wild-type; Mut, mutant; 3'UTR, 3'-untranslated region; PWAR6-OE, PWAR6 overexpression vector. 
(Fig. 4H). A dual-luciferase reporter assay was conducted to verify the interaction between $B M P 2$ and miR-106a-5p, which indicated that miR-106a-5p mimic significantly inhibited the luciferase activity of the $B M P 2-\mathrm{WT}$ reporter, but displayed a limited effect on the luciferase activity of the BMP2-Mut reporter compared with the negative control group (Fig. 4I).

\section{Discussion}

Inhibition of hPDLSC osteogenic differentiation under stimuli such as inflammation and hypoxia may result in the loss of periodontal connective tissues (35). The present study aimed to improve the current understanding of the regulation of hPDLSC osteogenesis and the mechanism underlying periodontal tissue loss. The results indicated that in OM-incubated cells, the expression levels of PWAR6 and four osteogenic-related proteins (Runx2, OCN, BMP2 and ALP) were increased compared with GM-incubated cells. Secondly, compared with the corresponding control groups, PWAR6 overexpression significantly increased osteogenesis, whereas PWAR6 knockdown led to the opposite result, which indicated that PWAR6 may serve a potential regulatory role during the osteogenesis of hPDLSCs.

Previous studies have investigated the role of PWAR6 in cancer and other diseases $(29,30)$. Lei et al (29) demonstrated that gene telomeric expression of the PWAR6 breakpoint significantly affects the pathogenesis of Prader-Willi syndrome. In addition, PWAR6 has a notable influence on the survival of patients with glioma and is involved in the immune response, DNA repair and epithelial-mesenchymal transition (30). However, the effects of PWAR6 on the osteogenesis of hPDLSCs have not been previously reported; therefore, to the best of our knowledge, the present study indicated for the first time that PWAR6 may positively regulate the osteogenic differentiation of hPDLSCs and their ALP activity by regulating osteogenic factors, such as Runx2, OCN and BMP2.

It has been reported that multiple lncRNAs serve as miRNAs sponges (36-41). Wu et al (36) revealed that lncRNA PAGBC displays a sponge effect on miR-133b and miR-511, which promotes metastasis and tumor growth of gallbladder cancer. Previous studies have demonstrated that the differentiation of mesenchymal stem cells into osteoblasts is regulated by miRNAs (42-44). The expression levels of miR-42, miR-106a, miR-148a, let-7i and miR-99a are specific in human mesenchymal stem cells, whereas the expression levels of miR-15b, miR-24, miR-130b, miR-30c and miR-130a are specific in differentiated osteoblasts (45). Vimalraj and Selvamurugan (45) indicated that miR-15b promotes adipogenesis and myogenesis lineages. By considering the sponging effect of IncRNAs, the present study further investigated the relationship between PWAR6 and miRNAs. The small non-coding RNA miR-106a-5p is involved in colorectal cancer, osteosarcoma and astrocytoma (46). Regarding the association of miR-106a-5p with osteogenesis, miR-106a-5p promotes apoptosis and suppresses cell proliferation (47). In the present study, miR-106a-5p expression was decreased in OM-incubated cells compared with GM-incubated cells. Furthermore, the results indicated that PWAR6 may serve as a sponge of miR-106a-5p to promote osteogenesis via upregulating osteogenic markers. Although other miRNAs, such as miR-1827, miR-145 and miR-5100, and their association with osteogenic differentiation have been previously reported (48-50), at present, little is known about the association between miR-106a-5p and osteogenesis. Based on the results of the present study, it was hypothesized that PWAR6 may regulate the osteogenesis of hPDLSCs by serving as a sponge of miR-106a-5p.

BMP2 induces chondrogenic differentiation, osteogenic differentiation and endochondral ossification of stem cells (51). BMP2 can influence the osteogenic differentiation of mesenchymal stem cells (52). BMP2-modified injectable hydrogel can be used for the osteogenic differentiation of human periodontal ligament stem cells (53). The results of the present study suggested that BMP2 was a target gene of miR-106a-5p, which was supported by Li et al (54), who demonstrated that miR-106a regulates osteogenesis and adipogenic lineage commitment of human mesenchymal stem cells by directly targeting BMP2. BMP2 is a vital differentiation-related factor that belongs to the transforming growth factor $\beta$ family, and can promote bone healing and induce bone growth $(55,56)$. The effect of PWAR6 on the osteogenic differentiation of hPDLSCs was preliminarily investigated in the present study, but the effects of proinflammatory factors on PWAR6 and miR-106a require further investigation.

In conclusion, the present study identified a possible interaction network between lncRNA PWAR6 and miR-106a-5p. PWAR6 may promote the osteogenic differentiation and mineralization of hPDLSCs and serve as a sponge of miR-106a-5p. The present study indicated that modulating the osteogenic differentiation of hPDLSCs may serve as a potential therapeutic strategy for periodontal disease.

\section{Acknowledgements}

Not applicable.

\section{Funding}

No funding was received.

\section{Availability of data and materials}

The datasets used and/or analyzed during the current study are available from the corresponding author on reasonable request.

\section{Authors' contributions}

JX and YB made substantial contributions to the conception and design of the study, acquired, analyzed and interpreted the data, and drafted or critically revised the article for important intellectual content. All authors read and approved the final manuscript.

\section{Ethics approval and consent to participate}

The present study was approved by the Ethics Committee of Jingmen No. 1 People's Hospital (approval no. Y20180831) and written consent was obtained from each participant. 


\section{Patient consent for publication}

Not applicable.

\section{Competing interests}

The authors declare that they have no competing interests.

\section{References}

1. Liu Y, Zeng X, Miao J, Liu C, Wei F, Liu D, Zheng Z, Ting K, Wang $\mathrm{C}$ and Guo J: Upregulation of long noncoding RNA MEG3 inhibits the osteogenic differentiation of periodontal ligament cells. J Cell Physiol 234: 4617-4626, 2019.

2. Pihlstrom BL, Michalowicz BS and Johnson NW: Periodontal diseases. Lancet 366: 1809-1820, 2005.

3. Xue P, Li B, An Y, Sun J, He X, Hou R, Dong G, Fei D, Jin F, Wang Q and Jin Y: Decreased MORF leads to prolonged endoplasmic reticulum stress in periodontitis-associated chronic inflammation. Cell Death Differ 23: 1862-1872, 2016.

4. Zhang $\mathrm{H}$ and Zhang D: Effects of periodontal ligament cells on alveolar bone metabolism under the action of force and inflammatory factors and its molecular mechanisms. Zhongguo Yi Xue Ke Xue Yuan Xue Bao 39: 432-437, 2017

5. Nagata M, Iwasaki K, Akazawa K, Komaki M, Yokoyama N, Izumi Y and Morita I: Conditioned medium from periodontal ligament stem cells enhances periodontal regeneration. Tissue Eng Part A 23: 367-377, 2017.

6. Liu N, Shi S, Deng M, Tang L, Zhang G, Liu N, Ding B, Liu W, Liu Y, Shi $\mathrm{H}$, et al: High levels of $\beta$-catenin signaling reduce osteogenic differentiation of stem cells in inflammatory microenvironments through inhibition of the noncanonical Wnt pathway. J Bone Miner Res 26: 2082-2095, 2011.

7. Zhang J, Li ZG, Si YM, Chen B and Meng J: The difference on the osteogenic differentiation between periodontal ligament stem cells and bone marrow mesenchymal stem cells under inflammatory microenviroments. Differentiation 88: 97-105, 2014.

8. Jia B, Qiu X, Chen J, Sun X, Zheng X, Zhao J, Li Q and Wang Z: A feed-forward regulatory network 1 cPCAT1/miR-106a-5p/E2F5 regulates the osteogenic differentiation of periodontal ligament stem cells. J Cell Physiol 234: 19523-19538, 2019.

9. Wei F, Yang S, Guo Q, Zhang X, Ren D, Lv T and Xu X MicroRNA-21 regulates osteogenic differentiation of periodontal ligament stem cells by targeting Smad5. Sci Rep 7: 16608, 2017.

10. Yan GQ, Wang X, Yang F, Yang ML, Zhang GR, Wang GK and Zhou Q: MicroRNA-22 promoted osteogenic differentiation of human periodontal ligament stem cells by targeting HDAC6. J Cell Biochem 118: 1653-1658, 2017.

11. Gu X, Li M, Jin Y, Liu D and Wei F: Identification and integrated analysis of differentially expressed lncRNAs and circRNAs reveal the potential ceRNA networks during PDLSC osteogenic differentiation. BMC Genet 18: 100, 2017.

12. Ugawa Y, Yamamoto T, Kawamura M, Yamashiro K, Shimoe M, Tomikawa K, Hongo S, Maeda H and Takashiba S: Rho-kinase regulates extracellular matrix-mediated osteogenic differentiation of periodontal ligament cells. Cell Biol Int 41: 651-658, 2017.

13. Kang W, Liang Q, Du L, Shang L, Wang T and Ge S: Sequential application of bFGF and BMP-2 facilitates osteogenic differentiation of human periodontal ligament stem cells. J Periodontal Res 54: 424-434, 2019.

14. Lee JS, Lee JC and Heo JS: Polydopamine-assisted BMP-2 immobilization on titanium surface enhances the osteogenic potential of periodontal ligament stem cells via integrin-mediated cell-matrix adhesion. J Cell Commun Signal 12: 661-672, 2018.

15. Cao F, Zhan J, Chen X, Zhang K, Lai R and Feng Z: miR-214 promotes periodontal ligament stem cell osteoblastic differentiation by modulating Wnt $/ \beta$-catenin signaling. Mol Med Rep 16 : 9301-9308, 2017.

16. Li S, Shao J, Zhou Y, Friis T, Yao J, Shi B and Xiao Y: The impact of Wnt signalling and hypoxia on osteogenic and cementogenic differentiation in human periodontal ligament cells. Mol Med Rep 14: 4975-4982, 2016

17. Chen LJ, Hu BB, Shi XL, Ren MM, Yu WB, Cen SD, Hu RD and Deng H: Baicalein enhances the osteogenic differentiation of human periodontal ligament cells by activating the Wnt/ $\beta$-catenin signaling pathway. Arch Oral Biol 78: 100-108, 2017.
18. Wang L, Wu F, Song Y, Li X, Wu Q, Duan Y and Jin Z: Long noncoding RNA related to periodontitis interacts with miR-182 to upregulate osteogenic differentiation in periodontal mesenchymal stem cells of periodontitis patients. Cell Death Dis 7: e2327, 2016.

19. Zhang J, Wang P, Wan L, Xu S and Pang D: The emergence of noncoding RNAs as Heracles in autophagy. Autophagy 13: 1004-1024, 2017.

20. Cech TR and Steitz JA: The noncoding RNA revolution-trashing old rules to forge new ones. Cell 157: 77-94, 2014.

21. Sharp PA: The centrality of RNA. Cell 136: 577-580, 2009.

22. Zhuang W, Ge X, Yang S, Huang M, Zhuang W, Chen P, Zhang X, Fu J, Qu J and Li B: Upregulation of lncRNA MEG3 promotes osteogenic differentiation of mesenchymal stem cells from multiple myeloma patients by targeting BMP4 transcription. Stem Cells 33: 1985-1997, 2015.

23. Zhang W, Dong R, Diao S, Du J, Fan Z and Wang F: Differential long noncoding RNA/mRNA expression profiling and functional network analysis during osteogenic differentiation of human bone marrow mesenchymal stem cells. Stem Cell Res Ther 8: 30 , 2017.

24. Liao J, Yu X, Hu X, Fan J, Wang J, Zhang Z, Zhao C, Zeng Z, Shu Y, Zhang R, et al: lncRNA H19 mediates BMP9-induced osteogenic differentiation of mesenchymal stem cells (MSCs) through Notch signaling. Oncotarget 8: 53581-53601, 2017.

25. Memczak S, Jens M, Elefsinioti A, Torti F, Krueger J, Rybak A, Maier L, Mackowiak SD, Gregersen LH, Munschauer M, et al: Circular RNAs are a large class of animal RNAs with regulatory potency. Nature 495: 333-338, 2013.

26. Hansen TB, Jensen TI, Clausen BH, Bramsen JB, Finsen B, Damgaard CK and Kjems J: Natural RNA circles function as efficient microRNA sponges. Nature 495: 384-388, 2013.

27. Beermann J, Piccoli MT, Viereck J and Thum T: Non-coding RNAs in development and disease: Background, mechanisms, and therapeutic approaches. Physiol Rev 96: 1297-1325, 2016.

28. Mozaffari SV, Stein MM, Magnaye KM, Nicolae DL and Ober C: Parent of origin gene expression in a founder population identifies two new candidate imprinted genes at known imprinted regions. PLoS One 13: e0203906, 2018.

29. Lei M, Mitsuhashi S, Miyake N, Ohta T, Liang D, Wu L and Matsumoto N: Translocation breakpoint disrupting the host SNHG14 gene but not coding genes or snoRNAs in typical Prader-Willi syndrome. J Hum Genet 64: 647-652, 2019.

30. Lin X, Jiang T, Bai J, Li J, Wang T, Xiao J, Tian Y, Jin X, Shao T, $\mathrm{Xu}$ J, et al: Characterization of transcriptome transition associates long noncoding RNAs with glioma progression. Mol Ther Nucleic Acids 13: 620-632, 2018

31. Du L, Yang P and Ge S: Isolation and characterization of human gingiva-derived mesenchymal stem cells using limiting dilution method. J Dent Sci 11: 304-314, 2016.

32. Wang T, Kang W, Du L and Ge S: Rho-kinase inhibitor Y-27632 facilitates the proliferation, migration and pluripotency of human periodontal ligament stem cells. J Cell Mol Med 21: 3100-3112, 2017.

33. Li JH, Liu S, Zhou H, Qu LH and Yang JH: starBase v2.0: Decoding miRNA-ceRNA, miRNA-ncRNA and protein-RNA interaction networks from large-scale CLIP-Seq data. Nucleic Acids Res 42 (Database Issue): D92-D97, 2014.

34. Livak KJ and Schmittgen TD: Analysis of relative gene expression data using real-time quantitative PCR and the 2(-Delta Delta C(T)) method. Methods 25: 402-408, 2001.

35. Bae WJ, Shin MR, Kang SK, Zhang-Jun, Kim JY, Lee SC and Kim EC: HIF-2 inhibition supresses inflammatory responses and osteoclastic differentiation in human periodontal ligament cells. J Cell Biochem 116: 1241-1255, 2015.

36. Wu XS, Wang F, Li HF, Hu YP, Jiang L, Zhang F, Li ML, Wang XA, Jin YP, Zhang YJ, et al: LncRNA-PAGBC acts as a microRNA sponge and promotes gallbladder tumorigenesis. EMBO Rep 18: 1837-1853, 2017.

37. Ballantyne MD, McDonald RA and Baker AH: lncRNA/ MicroRNA interactions in the vasculature. Clin Pharmacol Ther 99: 494-501, 2016.

38. Wang K, Jin W, Song Y and Fei X: LncRNA RP11-436H11.5, functioning as a competitive endogenous RNA, upregulates $\mathrm{BCL}-\mathrm{W}$ expression by sponging miR-335-5p and promotes proliferation and invasion in renal cell carcinoma. Mol Cancer 16: 166, 2017.

39. Kallen AN, Zhou XB, Xu J, Qiao C, Ma J, Yan L, Lu L, Liu C, Yi JS, Zhang H, et al: The imprinted H19 lncRNA antagonizes let-7 microRNAs. Mol Cell 52: 101-112, 2013 
40. Yu C, Li L, Xie F, Guo S, Liu F, Dong N and Wang Y: LncRNA TUG1 sponges miR-204-5p to promote osteoblast differentiation through upregulating Runx2 in aortic valve calcification. Cardiovasc Res 114: 168-179, 2018.

41. Kim J, Abdelmohsen K, Yang X, De S, Grammatikakis I, Noh JH and Gorospe M: LncRNA OIP5-AS1/cyrano sponges RNA-binding protein HuR. Nucleic Acids Res 44: 2378-2392, 2016.

42. Guo L, Zhao RC and Wu Y: The role of microRNAs in self-renewal and differentiation of mesenchymal stem cells. Exp Hematol 39: 608-616, 2011.

43. Zhang Z, Liu J, Zeng Z, Fan J, Huang S, Zhang L, Zhang B, Wang X. Feng Y, Ye Z, et al: lncRNA Rmst acts as an important mediator of BMP9-induced osteogenic differentiation of mesenchymal stem cells (MSCs) by antagonizing Notch-targeting microRNAs. Aging (Albany NY) 11: 12476-12496, 2019.

44. Seenprachawong K, Nuchnoi P, Nantasenamat $C$, Prachayasittikul V and Supokawej A: Computational identification of miRNAs that modulate the differentiation of mesenchymal stem cells to osteoblasts. PeerJ 4: e1976, 2016.

45. Vimalraj S and Selvamurugan N: MicroRNAs expression and their regulatory networks during mesenchymal stem cells differentiation toward osteoblasts. Int J Biol Macromol 66: 194-202, 2014.

46. Pan YJ, Wei LL, Wu XJ, Huo FC, Mou J and Pei DS: MiR-106a-5p inhibits the cell migration and invasion of renal cell carcinoma through targeting PAK5. Cell Death Dis 8: e3155, 2017.

47. Hai B, Ma Y, Pan X, Yong L, Liang C, He G, Yang C, Zhu B and Liu X: Melatonin benefits to the growth of human annulus fibrosus cells through inhibiting miR-106a-5p/ATG7 signaling pathway. Clin Interv Aging 14: 621-630, 2019.

48. Hao W, Liu H, Zhou L, Sun Y, Su H, Ni J, He T, Shi P and Wang X: MiR-145 regulates osteogenic differentiation of human adipose-derived mesenchymal stem cells through targeting FoxO1. Exp Biol Med (Maywood) 243: 386-393, 2018.
49. Zhu S, Peng W, Li X, Weng J, Zhang X, Guo J, Huang D, Rong Q and Chen S: miR-1827 inhibits osteogenic differentiation by targeting IGF1 in MSMSCs. Sci Rep 7: 46136, 2017.

50. Wang H, Cui Y, Luan J, Zhou X, Li C, Li H, Shi L and Han J: MiR-5100 promotes osteogenic differentiation by targeting Tob2. J Bone Miner Metab 35: 608-615, 2017.

51. Zhou N, Li Q, Lin X, Hu N, Liao JY, Lin LB, Zhao C, Hu ZM, Liang X, Xu W, et al: BMP2 induces chondrogenic differentiation, osteogenic differentiation and endochondral ossification in stem cells. Cell Tissue Res 366: 101-111, 2016.

52. Sun MH, Wang WJ, Li Q, Yuan T and Weng WJ: Autologous oxygen release nano bionic scaffold composite miR-106a induced BMSCs enhances osteoblast conversion and promotes bone repair through regulating BMP-2. Eur Rev Med Pharmacol Sci 22: 7148-7155, 2018

53. Park SH, Kwon JS, Lee BS, Park JH, Lee BK, Yun JH, Lee BY, Kim JH, Min BH, Yoo TH and Kim MS: BMP2-modified injectable hydrogel for osteogenic differentiation of human periodontal ligament stem cells. Sci Rep 7: 6603, 2017.

54. Li H, Li T, Wang S, Wei J, Fan J, Li J, Han Q, Liao L, Shao C and Zhao RC: miR-17-5p and miR-106a are involved in the balance between osteogenic and adipogenic differentiation of adipose-derived mesenchymal stem cells. Stem Cell Res 10: 313-324, 2013

55. Oliveira OR, Martins SP, Lima WG and Gomes MM: The use of bone morphogenetic proteins (BMP) and pseudarthrosis, a literature review. Rev Bras Ortop 52: 124-140, 2016.

56. Bais MV, Wigner N, Young M, Toholka R, Graves DT, Morgan EF, Gerstenfeld LC and Einhorn TA: BMP2 is essential for post natal osteogenesis but not for recruitment of osteogenic stem cells. Bone 45: 254-266, 2009.

This work is licensed under a Creative Commons Attribution-NonCommercial-NoDerivatives 4.0 International (CC BY-NC-ND 4.0) License. 